\title{
Serial Transplantation
}

National Cancer Institute

\section{Source}

National Cancer Institute. Serial Transplantation. NCI Thesaurus. Code C122938.

The transfer of a graft from a primary recipient into a secondary recipient. 